\title{
DETAILED MORPHOLOGY OF THE RICH CONCENTRATED GALAXY CLUSTERS
}

\author{
E. Panko ${ }^{1}$, A. Sirginava ${ }^{1}, \&$ A. Stepaniuk ${ }^{2}$ \\ 1 Department of Theoretical Physics and Astronomy, \\ I. I. Mechnikov Odessa National University Odessa, Ukraine \\ panko.elena@gmail.com \\ ${ }^{2}$ Lohika Company, Odessa, Ukraine
}

\begin{abstract}
The results of the detailed analysis of the $2 D$ distribution of galaxies in 28 rich galaxy clusters with significant concentration to the cluster center are present. The analysis was executed in these directions: the detection of regular substructures and peculiarities in the galaxy distribution. The role of brightest cluster members was taken into account too. The input data were selected from "The Catalogue of Galaxy Clusters and Groups" and list of galaxies of Muenster Red Sky Survey. Concentrated galaxy clusters are evolved, virialized structures. Substructures in this type of clusters must be feeble marked. Nevertheless we detected significant part of concentrated galaxy clusters having different kinds of peculiarities, namely crossing and divaricating filaments or $\mathrm{X}$ and Y-type peculiarities, as well as curved strips and short dense chains. 2 clusters having extremely density of galaxies were attributed as superconcentrated/compact type.
\end{abstract}

Key words: Galaxies: clusters: morphology, peculiarities

АБСТРАКТ. Ми представляємо результати детального аналізу $2 D$ розподілу галактик у 28 багатих скупченнях галактик зі значущою концентрацією до центру (С-тип). Спостережною основою для дослідження був "Каталог скупчень та груп галактик", створений на базі Списку галактик Мюнстерского Червоного Огляду Неба. у "Каталозі скупчень та груп галактик" $€ 460$ скупчень, у полі яких знаходиться 100 та більше галактик. Вдосконалена схема морфологічної класифікапії скупчень галактик, враховує концентрацію до центру скупчення, наявність у скупченні виділеної смуги - широкої (F-тип) або вузької (L-тип). Роль найяскравіших галактик також приймається до уваги. Відповідно доо попереднього розподілу на концентровані $\mathrm{C}$, проміжні I та розсіяні О скупчення, набір концентрованих скупчень $е$ найменшим.

Під час дослідження для кожного скупчення біло побудовано його мапу у проекції на картину площину у ідеальних координатах та проаналізовано варіації поверхневої густини галактик. Крім наявності статистично значущих стандартних особливостей, яки у морфологічній схемі відповідають типам 3 виділеною смугою, було знайдено також інші значуші пекулярності. Скупчення галактик 3 великою концентрапією до центру, відповідно до сучасних уявлень, повинні бути віріалізованими структурами. Підструктури в цьому типу скупчень, скориш за все, є слабо вираженими. Проте ми виявили, що серед скупчень, що досліджувалися, понад 40

Ключові слова: Галактики: скупчення: морфологія, пекулярності.

\section{Introduction}

Distribution of galaxies both in the space and on the celestial sphere reflected the primordial adiabatic fluctuations in beginning moments of Universe, as it shown in big number of works from Silk (1968), Peebles \& Yu (1970), Sunyaew \& Zeldovich (1970) to well quoted Millennium Simulation (Springel et al., 2005), Illustris Project (Vogelsberger et al., 2014; Artale et al., 2017). The galaxy clusters are the essential component of large-scale structure of Universe in the chain galaxies $\Rightarrow$ galaxy groups $\Rightarrow$ galaxy clusters $\Rightarrow$ galaxy superclusters. From the other hand, galaxy clusters are the special component of large-scale structure because time of virialization of biggest ones is only one order less than age of Universe. Taking into consideration the results of different numerical simulations (from Springel et al., 2005 to, for example, Cui et al., 2018) described arising the knots, filaments, sheets and voids, the galaxy clusters are evolving and colliding objects. The evidences of collisions of galaxy clusters are 
detected and analyzed. The collided and interacted galaxy clusters show different distribution of intercluster galaxies, hot gas and DM (Markevitch et al., 2004, Pearce at al., 2017).

The evolution of non-collided galaxy clusters is determined mainly own gravitation. For this case the signs of cluster evolution can be defined according their morphological type. Evidently, galaxy population is not main component in a clusters, however galaxy fraction is seen in optic, and the presence or absence the peculiarities in distribution of galaxies inside the cluster can be easyly detected.

Proposed by Panko (2013) classical schemes summarizes the classical approach (Abell, 1958; Zwicky et al., 1961 - 1968, Bautz \& Morgan, 1970; Rood \& Sastry, 1971 and López-Cruz, 2003). The improved types correspond to concentration to the center (C - compact, I - intermediate, and $\mathrm{O}$ - open), preferential line presence ( $\mathrm{L}$ - line, $\mathrm{F}$ - flat, and no symbol if no indication of flatness is present) and the role of bright cluster members, namely cD or BG if the bright cluster's members (BCMs) role is significant. Other peculiarities are noted as $\mathrm{P}$. The special kinds of regular peculiarities, such as X-type (crossed bands) and Y-type (divaricate filaments) with corresponding positions and orientations of the BCMs; curved strips and short chains were detected in open rich clusters (Panko \& Emelyanov, 2017; Panko et al., 2018).

According to idea Rood \& Sastry (1971) and Struble \& Rood (1982) confirmed in simulations (for example, Vogelsberger et al., 2014; Artale et al., 2017) the galaxy clusters evolve form open to concentrated types. We suppose the influence of neighbours becomes apparent as regular peculiarities.

The paper is organized in the standard manner. Section 2 contains the description of the observational data and the cluster mapping, section 3 presents the characters of substructures, distribution clusters according to subtypes and its analysis, and section 4 conclusions and analysis is given at the end.

\section{Observational Data and Mapping}

The present study is the part of common analysis of properties of rich galaxy clusters selected from "A Catalogue of Galaxy Clusters and Groups" (Panko \& Flin, 2006, hereafter PF). The PF Catalogue contains 460 galaxy clusters with richness 100 and more. According previous classification the set contains 28 concentrated, 178 intermediate and 254 open galaxy clusters. The last subset was analyzed by Panko \& Emelyanov (2017). The 178 intermediate clusters were studied by Zabolotnii et al. (in preparation). The difference between O-type and other ones was established by Panko et al. (2016) on subset of rich PF galaxy clusters coinciding to ACO objects (Abell, Corwin \& Olowin, 1989).
The information about individual galaxies in the cluster field is obtained from Münster Red Sky Survey Galaxy Catalogue (Ungrue et al., 2003). For determination of morphological type we used improved program "The Cluster Cartography set" (Panko \& Emelyanov, 2015, hereafter CC). The CC allows to construct cluster map in rectangular coordinates in arcseconds recalculated from standard equatorial. The symbols on the map illustrate the galaxy shape and orientation in the projection on the celestial sphere, but size of symbol corresponds to galaxy magnitude; calculation bases on MRSS data. Additional brightest galaxies can be marked by darker shades of gray.

$\mathrm{CC}$ allows us to find the overdense regions as circles on case of $C$ - and $I$-types of clusters or as belts/strips for $L$ and $F$ clusters. In the last case the clusters field is divided to $N$ bands. $N$ can be $3,5,7,9$ or 11 and the width of each band is $1 / N$ part of diameter of cluster. The numbers of galaxies in the bands are recalculated to weighted densities of galaxies (Panko \& Emelyanov, 2015). It allows to describe overdense features as $L 11$ or $L 9$ for $L$-cluster and $F 7$ or $F 5$ for $F$-clusters (the numeral part corresponds $N$ ). For $\mathrm{C}$ and I types the central part of cluster was excluded from overdense features search. The crossing bands, divaricate filaments, curved strips and short chains inside the cluster can be detected according to weighted densities in the sectors.

\section{The Subtypes and Peculiarities in Con- centration Galaxy Clusters}

Our detailed analysis of the distribution of galaxies in concentrated galaxy clusters allows to confirm attribution to C-type without signs of the preferential band only for 15 clusters.

Table 1: The distribution C-type PF galaxy clusters by subtypes

\begin{tabular}{ccccccccc} 
Type & $N$ & cD & BG & P & PX & PY & $\begin{array}{c}\text { P } \\
\text { shc }\end{array}$ & $\begin{array}{c}\text { Prv } \\
\text { crv }\end{array}$ \\
\hline C & 12 & 4 & 5 & 4 & & 2 & 1 & 1 \\
CF & 9 & 1 & 5 & 5 & & 2 & 2 & 1 \\
CL & 3 & & 1 & 2 & 1 & 1 & & \\
SC & 2 & & & & & & & \\
CI & 2 & 1 & 1 & 1 & & 1 & 1 & \\
\hline All & 28 & 6 & 15 & 12 & 1 & 5 & 4 & 2 \\
\hline
\end{tabular}

These 2 clusters show a special level of overdensity and can be described as compact or superconcentrated (SC-type). The example of SC-type cluster is shown in Fig 1, left panel. SC-type clusters have no peculiarities. At the same time in SC-type clusters we found 

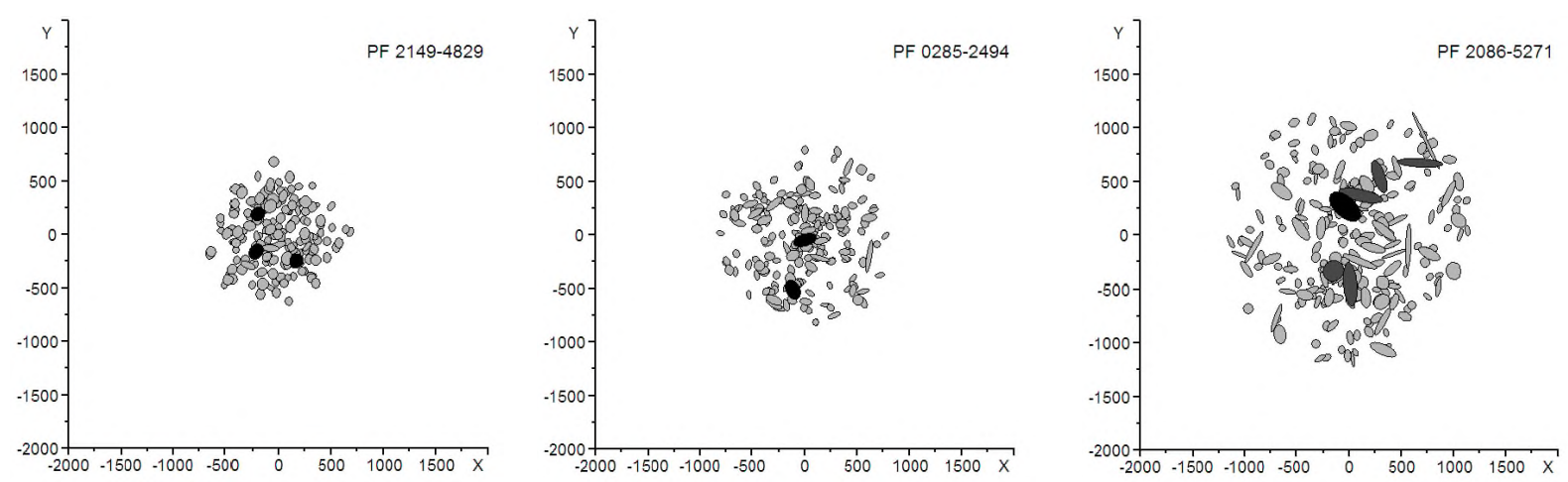

Figure 1: The map of galaxy cluster PF 2149-4829 SC-type and clusters with Y-type peculiarities: PF 0285-2494 and PF 2086-5271 with 2 centers of concentration. Axes labels are given in arcseconds.

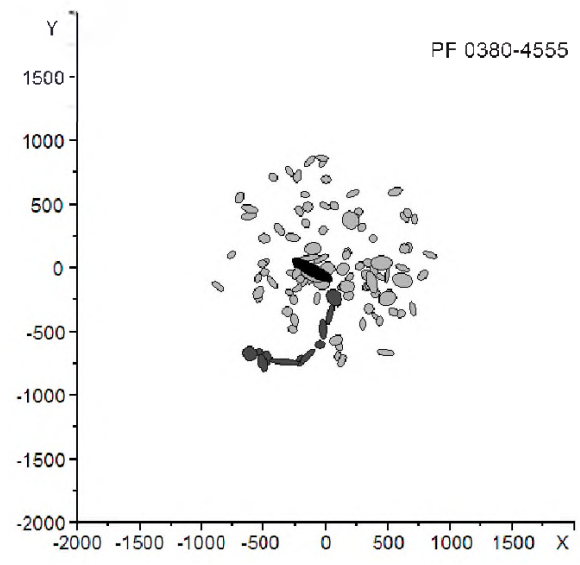

Figure 2: The map of galaxy cluster PF 0380-4555 with curved strip. The galaxies in the filamentary substructure are shown as light grey symbols, brightest galaxy is black one.

extremely big part of galaxies with small ellipticities.

2 C-type clusters from 12 have $Y$-type substructures underscore the positions of BCMs (Fig 1, central and right panels). For another $2 \mathrm{C}$-type clusters we found short chain (shc) and curved strip (crv) peculiarities. The curved strip in PF 0380-4555 is shows in Fig. 2. The founded filamentary substructure requires separate study.

12 clusters having preferential bands were attributed as CF or CL types and 2 clusters were determined as CI-type. The distribution of galaxy clusters of our data subset is shown in Table 1.

The part of galaxies with big and small ellipticities (as way to estimation $\mathrm{E} / \mathrm{S}$ ratio) is different in normal and peculiar clusters. At the same time, peculiar clusters have essential part of galaxies with big ellipticity and a small part of E galaxies correspondingly.

\section{Discussion and conclusions}

From the previous study the morphology of galaxy clusters (Panko et al., 2016) based on 247 Rich PF Galaxy Clusters we established the special role of concentrated galaxy clusters - Regular ones according to Abell (1958) and Compact in Zwicky et al. (1968) schemes. The alignment of the brightest galaxy according to parent cluster is statistically significant in C-type clusters. Nevertheless we found the presence of overdense belt in about $40 \%$ clusters in our data set. For these clusters alignment of brightest galaxy as well as positions and orientations for 2 or 3 BCMs corresponds to direction of found belt.

The $\mathrm{X}$-type (crossed belts) peculiarity was detected only in 1 case in contrary to $\mathrm{Y}$-type discovered in 5 clusters. The $\mathrm{E} / \mathrm{S}$ ratio points out the dependence of Hubble mix from interactions between galaxies in substructures. It confirmed the result Panko \& Flin (2014) which was not find the hard connection $\mathrm{E} / \mathrm{S}$ ratio with basic morphology types. In Panko \& Flin (2014) paper the presence of peculiarities was not considered.

The orientation of low mass galaxies in filamentary substructures corresponds to Binggeli (1982) effect (Fig. 2), in contrary to high-mass galaxies (Fig. 1, right pane). High-mass galaxies tend to alignment crosswise to overdense strip direction.

We studied the morphological characters of 28 concentrated galaxy clusters. We obtained the list of galaxy clusters with regular substructures of different kinds. We showed the signs of interactions and/or evolution in concentrated galaxy clusters are present. We detected the special types of regular substructures namely curved and short strips in the concentrated galaxy clusters. We detected the alignment of galaxies in regular substructures according to preferential direction or direction to neighbours. We found the vari- 
ations of $\mathrm{E} / \mathrm{S}$ ratio for galaxies in cluster is connected with presence of peculiarities and can be explained by interactions between galaxies in substructures.

Acknowledgements. This research has made use of NASA's Astrophysics Data System.

\section{References}

Abell G. O.: 1958, ApJS, 3, 211.

Abell G. O., Corwin H. G. \& Olowin R. P.: 1989, ApJS 70, 1.

Artale M. C., Pedrosa S. E., Trayford J. W. et al.: 2017, MNRAS 470, 1771.

Bautz L. P. \& Morgan W. W.: 1970, ApJ 162, L149.

Binggeli B.: 1982 A $6 A, \mathbf{1 0 7}, 338$.

Cui W., Knebe A., Yepes G.: 2018, MNRAS, 473, 68 .

Lóopez-Cruz O., "The Classification of Clusters of Galaxies: Comments on the Proposal of a New Subclass", in: "The Garrison Festschrift: Contribution of the Institute for Space Observations", No 20, R. O. Gray, C. J. Corbally, A. G. D. Philip (eds.): 2003, 109.

Markevitch M., Gonzalez A. H., Clowe D., at al.: 2004, ApJ, 606, 819.

Panko E. \& Flin P.: 2006, Journal of Astronomical Data, 12, 1.

Panko E. A.: 2013, Odessa Astr. Publ., 26, 90.

Panko E. A \& Flin P.: 2014, Odessa Astr. Publ., 27, 32.

Panko E. A \& Emelyanov S. I.: 2015, Odessa Astr. Publ., 28, 135 .
Panko E., Bajan K., Flin P. \& Gotsulyak A., "Morphological Types of 247 PF Galaxy Clusters", in: "The Zeldovich Universe: Genesis and Growth of the Cosmic Web", Proceedings of the International Astronomical Union, IAU Symposium, Volume 308, R. van de Weygaert, S. Shandarin, E. Saar \& J. Einasto (eds.):2016, 213.

Panko E. A \& Emelyanov S. I.: 2017, Odessa Astr. Publ., 30, 121.

Panko E., Andrievsky S., Yemelianov S. \& Stepaniuk A.: 2018, Astronomy Reports, in press.

Pearce C. J. J., van Weeren R. J., AndradeSantos F., et al.: 2017, ApJ, 845, 81 .

Peebles P. J. E. \& Yu J. T.: 1970, ApJ, 162, 815.

Rood H. J. \& Sastry G. N.: 1971, PASP, 83, 313.

Silk J.: 1968, ApJ, 151, 459.

Springel V., White S. D., Jenkins A., et al.: 2005, Nature, 435, 629.

Struble M. F. \& Rood H. J.: 1982, ApJ, 87, 7.

Sunyaev R. A. \& Zeldovich Ya. B.: 1970, ApSS, 7, 3 .

Ungruhe R., Saitter W. C. \& Durbeck H. W.: 2003, Journal of Astronomical Data, 9, 1.

Vogelsberger M., Genel Shy, Springel V., et al.:2014, MNRAS, 444, 1518.

Zabolotnii V., Panko E. \& Yemelianov S., (in preparation).

Zwicky F., Herzog E., Wild P., "Catalogue of galaxies and of clusters of galaxies" (1961 - 1968). 